\title{
Understanding the Distracted and the Disinhibited: Experiences of Adolescents Diagnosed with ADHD Within the South African Context
}

\author{
J. Seabi* and N.A. Economou \\ Department of Psychology, School of Human and Community Development, \\ University of the Witwatersrand, \\ South Africa
}

\section{Introduction}

This chapter explores how adolescents diagnosed with Attention Deficit Hyperactivity Disorder (ADHD) make sense of their condition, how they feel about their difficulties and how they perceive themselves and their reality within the South African context. This chapter is presented against the backdrop of more than thirty years of well-established research that has largely focused on assessment, diagnosis, management and treatment of the condition. The intention of this chapter is to examine how adolescents perceive ADHD as it relate to their lives. The accounts contained in the research provide insights into the lives and minds of young people who have been diagnosed as having ADHD. Qualitative approach was employed and data was collected via semi-structured interviews. The sample comprised five adolescents, all outpatients of Chris Hani Baragwanath's Child and Adolescent Psychiatric Unit. Through a process of thematic content analysis the data was analyzed and major themes were identified and interpreted.

\section{Rationale}

Attention Deficit Hyperactivity Disorder is currently the most commonly diagnosed behavioral childhood disorder and the diagnosis is without doubt controversial. ADHD continues to receive ongoing attention from parents, members of education systems, health professionals and researchers. In the United States of America, between 30 percent and 40 percent of all children who are referred to child clinics and centers have been diagnosed with ADHD (Bird, 2002; Timimi \& Taylor, 2004; Polanczk, de Lima, Horta, Biederman \& Rohde, 2007). The prevalence rates in South Africa and Africa are reported to be just as high as in Western countries (Aase, Meyer, Sagvolden, 2006; Adewuya \& Famuyiwa, 2007, Louw, Oswald \& Perold, 2009; Seabi, 2010; Van der Westhuizen, 2010). It is thus imperative that the psychological and educational domains embrace and work with this condition. 
Despite the limited studies (Meyer, Eilertsen, Sundet, Tshifularo \& Sagvolden, 2004; Mahomedy, van der Westhuizen, van der Linde \& Coetsee, 2007) conducted within the African continent, not much is known about experiences and knowledge of adolescents with ADHD in Africa. To exacerbate the situation, ADHD is the most prevalent child psychiatric disorder in South Africa (Mahomedy et al., 2007; Perold, Louw \& Kleynhans, 2010).

To date, over thirty years of research has been invested in the understanding of ADHD. Knowledge of the condition, with particular reference to, diagnosis, management and treatment, is well-established and documented (Goldman, Genel, Bezman \& Slanetz, 1998; Polanczk et al., 2007). Without this significant body of work, educationalists and health professionals would not be in a position to intervene or treat the child who presents with the disorder.

However, the time has now arrived for the attention to be shifted. Research needs to focus on how the child with ADHD experiences the condition, as well as the impact it has on his/her emotional and social well-being. Given a recent finding which demonstrated that psychotropic drugs such as Ritalin and Adderall may produce a placebo effect- not in the children, but in their teachers, parents and other concerned adults who examine them (Nauert, 2009), it seems pertinent to understand how those who take these medications experience them. There appears to be a gap in the literature especially within the South African context regarding the child's personal experience of living with a diagnosis of ADHD. In this way, those who work with the condition will gain a better understanding.

While it is common for ADHD to have been diagnosed in early childhood, it is a misconception that the adolescent outgrows the disorder. Van der Westhuizen (2010) concurs that ADHD was believed to resolve around puberty as most hyperactive children become less hyperactive around this time, but symptoms of impulsivity and inattention usually persist in adulthood. Recent studies reveal that around 30\% to $70 \%$ of children experience problems related to ADHD in adulthood (Louw et al., 2009; Mahomedy et al., 2007).

Since adolescence is in itself a complicated developmental stage, it seems particularly significant to explore how adolescents with ADHD view their world. Adolescents with ADHD are more prone to engaging in high-risk behaviors such as drug use, early smoking and sexual activity than their peers without ADHD (Lambert \& Hartsough, 1998). Aase et al. (2006) are in agreement that the disorder places an adolescent at a risk for school failure, criminality, substance abuse and sexual promiscuity.

Research indicates that interpersonal relationships become increasingly difficult as children with ADHD enter preadolescence (Kendall, 2000; Mercugliano, 1999). Mash and Wolfe (2005) confirm that children diagnosed with ADHD often experience interpersonal problems with family members, educators and peers. Their behavior is often unpredictable, hostile and confrontational with an inability to learn from their past mistakes. Therefore, research needs to be conducted on how these adolescents make sense of their condition, how they perceive themselves in the world, how they see the condition to have impacted on their development and their responses to interventions they have received.

Consequently, the intention of this chapter is to examine how adolescents perceive and experience ADHD. The accounts contained in the research provide insights into the lives 
and minds of young people who have been diagnosed as having ADHD. This chapter is intended to be useful to parents, teachers, health professionals, support groups and other researchers, to further the understanding, definition and treatment of ADHD.

\subsection{Subtypes of ADHD}

Briefly, to date, three subtypes of ADHD are currently recognized in the Diagnostic and Statistical Manual of Mental Disorders, Fourth Edition (DSM-IV), namely, Predominantly Inattentive Type, Predominantly Hyperactive-Impulse and a Combined Type (American Psychiatric Association, 1994). The Combined subtype is the most commonly represented subgroup, followed by the Inattentive type (Biedermann, Willens \& Spencer, 2002). In Europe however, different criteria are used from the ICD-10 (International Classification of Diseases) and the condition is known as Hyperkinetic Disorder (Schroeder \& Gordon, 2002). In South Africa, the aid medical insurances require ICD-10 codes when service providers submit claims and as a result, the ICD-10 is largely used than the DSM-IV.

Regarding symptomatology, Barkley (2002) defines ADHD as having a constellation of symptoms, characterized by three hallmark symptoms; inattention, hyperactivity, and impulsivity. Barkley (1998) calls these symptoms the 'holy trinity' and asserts that they give rise to problems with inhibiting, initiating or sustaining responses to tasks and adhering to rules or instructions. Furthermore, it creates significant impairment in both the home and school environment (Van der Westhuizen, 2010). ADHD like any other Disruptive Behaviour Disorders, it is regarded as an externalizing disorder, in the sense that the behavior is usually more upsetting to others than to those with ADHD themselves (Holz \& Lessing, 2002).

Constructs around attention include alertness, arousal, selectivity, distractibility and sustained attention. Children and adolescents with chronic inattention experience their greatest difficulties with sustaining their attention. Inattentive symptoms include making careless mistakes, avoiding tasks, having difficulty listening to others and following instructions (Conners \& Jett, 2001). Impulsivity is commonly described as the inability to delay a response or a form of gratification. Blurting out comments inappropriately or butting into conversations are manifestations of this symptom (Conners \& Jett, 2001). Impulsivity is also understood as behavioral disinhibition, the inability to regulate behavior by consequences and rules (Goldstein \& Goldstein, 1998). Hyperactivity signifies excessive restlessness - becoming easily aroused emotionally and physically - at an age or developmental stage that is inappropriate. Barkley (2002) purports that the nature of ADHD should not be understood as being characterized by heightened distractibility and hyperactivity, but rather by problems of behavioral disinhibition and the consistent lack of persistence to sustain attention (Goldstein \& Goldstein, 1998).

\subsection{ADHD across the lifespan}

A large body of literature relates predominantly to children who have been diagnosed with ADHD. However, research emphasizes the persistence of ADHD throughout the lifespan. A substantial number of adolescents do not fully outgrow ADHD symptoms. Longitudinal follow-up studies provide strong evidence of the high percentage and continuation of 
ADHD into adulthood (Amen, 2001; Biedermann et al., 2002). ADHD is now understood as a chronic lifetime disorder.

For a careful diagnosis, it is critical to understand the developmental course of ADHD. Many children with ADHD are said to be active in the womb. They are born as colicky infants who are restless sleepers, fussy eaters, are sensitive to noise and touch and have motor and attention deficits (Amen, 2001; Conners \& Jett, 2001). These symptoms appear to rise relatively early in childhood with the mean age onset being between 3-4 years (Barkley, 1998). As toddlers, they are noted to become excessively active and mischievous, extremely curious, use vigorous play, have excessive temper tantrums, are demanding of parental attention and have difficulty in completing developmental tasks (Amen, 2001).

Yet, the majority of children with ADHD are recognized when they enter school. This is at the developmental stage of middle childhood. According to Barkley (1998; 2002), once they are recognized, a major social burden is placed on them. It causes a tremendous distress for many of them and their parents. Contrary to what youth with ADHD are able to do, the ability to sit still, attend, inhibit impulsive behavior, cooperate, follow through on instructions, play and interact pleasantly is crucial to a successful academic career (Conners \& Jett, 2001). At home parents complain that their children with ADHD do not complete household chores and responsibilities. Parents come to recognize that they need supervision as children with ADHD become to be perceived as being immature (Rhee, Waldman, Hay \& Levy, 1999).

Research suggests that ADHD does not end in childhood and the majority of children with ADHD continue to exhibit symptoms into adolescence with $40-50 \%$ carrying a diagnosis of oppositional defiant disorder and conduct disorder (Barkley, 1998; Robin, 2002; Krueger \& Kendall, 2001). Longitudinal studies confirm that ADHD persist into mid-adolescence for at least $40 \%$ of the children diagnosed in childhood and $30 \%$ will continue to meet the diagnostic criteria for ADHD into adulthood (Holz \& Lessing, 2002; Schroeder \& Gordon, 2002). These studies revealed that changes in symptoms can decline with age. Results indicate that the frequency of parent and teacher reported hyperactivity-impulsivity symptoms decline slightly. It is understood that the symptoms of hyperactivity and impulsivity decline and inattention becomes predominant. As children get older they are diagnosed with ADHD Inattentive Type (Dupaul, Power, Anastopoulos, Reid, McGoey, et al., 1997). Conners and Jett (2001) report that although symptoms of hyperactivity may diminish, inattention and impulsivity persist and feelings of inner restlessness come to the fore.

Adolescence is a trying time and is renowned for being a complex stage of development. Its defining feature is transition, since developmentally, adolescence falls between childhood and adulthood. Adolescence is a dynamic interplay between external pressures, having to mature quickly as well as being held back or kept from independence. Above all, adolescence is marked by ambivalence (Bryant \& Coleman, 1994).

Much attention in current research is turning its focus to ADHD in adolescence (BradleyKlug \& Grier, 2000; Robin, 2002). Barkley (1990, p.266) encapsulate the difficulty of ADHD adolescence; "the adolescent years of ADHD individuals may be some of the most difficult because of the increasing demands of independent, responsible conduct, as well as the 
emerging social and physical changes in puberty. Issues of identity, peer group acceptance, dating and courtship and physical development and appearance erupt as a source of demands and distress which the ADHD adolescent must now cope".

As this is a stage marked with physical and biological changes, development of stronger peer relationships and assertion of independence from parents, it is significant to note how adolescents with ADHD cope in their day-to-day lives. The point made earlier is that, for any adolescent, the changes are challenging. For the ADHD adolescent, the transition is exacerbated (Bradley-Klug \& Grier, 2000).

Adolescents with ADHD are more likely to fail a grade, be suspended, expelled or drop out, have increased conflict, negative communication and have high risk taking behavior, bad driving habits, risky sexual behavior (Robin, 2002). Indeed studies reveal that ADHD can have a severe impact if not well managed on the learner's scholastic achievement and personal development (DuPaul \& Stoner, 1994; Gross, 1997). Consistent with these studies are the findings that scholastic underachievement has far-reaching effects for learners with ADHD, such as experiencing rejection by others and self-rejection (Holz \& Lessing, 2002). Furthermore, they report that ADHD learners' self-concepts and opportunities for the future are adversely affected.

The concern for ADHD teenagers is that the diagnosis in the stage of adolescence is elusive and it can be easily misdiagnosed as clinicians are less likely to consider ADHD as a possible diagnosis for behavioral problems. In addition, it is more difficult to obtain information from educators in secondary schools. Accurate diagnosis, awareness and recognition of the fact that the teenager might be suffering from ADHD are essential.

The impact of untreated ADHD on the adolescent is far more damaging for the teenager, immediate family and social context in which they live (Nahlik, 2004). Bierdermann et al. (2002) report that approximately 75\% of ADHD symptoms persist into young adulthood. The study showed that the symptoms of ADHD into adulthood included inattention, distractibility, impulsivity and occupational malfunction.

Although a large body of research on ADHD has been conducted largely in developed countries in Euro-Western countries, only two studies (Kendall, Hatton, Beckett \& Leo, 2003; Krueger \& Kendall, 2001) were conducted in the United States which explored the experiences of adolescents with ADHD, in order to uncover how they perceive and manage ADHD. Krueger and Kendall (2001) conducted a qualitative study on a sample of 11 adolescents with age ranges of 13 to 19, who have been diagnosed with the ADHD for at least two years. The findings revealed that participants described themselves in relation to their ADHD symptoms, rather than holding an identity distinct from the disorder. Their descriptions centered on inadequacy in girls and anger and defiance in boys. Of significant interest it was that they did not view ADHD as being a disorder and the cause of many of their difficulties, but rather, the negative attributes of ADHD appeared to be incorporated into their identity.

In another study, Kendall et al. (2003) further explored children's and adolescents' accounts of their experiences with ADHD. In-depth interviews were conducted with a sample of 39 children (67\% boys; 38\% African-American, 33\% Hispanic, 23\% Caucasian) with an age range of 6 to 17 years. The results yielded six themes which were clustered as the (1) 
problems. In this cluster, the participants reported the problems that got them into trouble. These problems could be categorized as learning and cognition problems such as their slower rate of learning. They perceived themselves to be different from their peers as they were constantly distracted and confused by what they were instructed to do. They also mentioned behavioral problems which included not being able to control themselves, fighting, throwing things and yelling at their peers and teachers. In addition, they reported emotional problems in which they spoke about ADHD in terms of feeling sad, frustrated, mad, ashamed and sad. They felt that their peers laughed at them and perceived them as being stupid.

The second theme involved (2) meaning and identity of ADHD, whereby "they spoke about ADHD in terms of who they were, rather than the symptoms they experienced" (Kendall et al., 2003, p. 120). For them, ADHD meant being hyper- that is being out of control and unable to concentrate as well as talking too much. It is reported that despite many of them believing that they had ADHD, they did not perceive it as an illness until an authority figure told them they had ADHD. For some, they did not see ADHD as an illness but rather as part of who they were and that they were different.

The participants reported about (3) pills, that they took medication at some point in their life and revealed both positive and negative outcomes. Positively, they perceived medicine as something that helped them a lot, to concentrate and to control their hyperactivity. Negative outcomes included the bad taste, headaches and stomachaches, as well as the fear and shame associated with taking pills to control their behavior.

It was found that (4) mom was the most helpful person, who reminded them of taking the medicine. They were concerned about the effects of ADHD on their mothers and families. The other themes involved (5) causes in terms of what they attributed ADHD to and (6) ethnicity as different races described themselves differently. The implication of this study points out to the importance of and necessities of educators, parents, nurses, psychologists and others in providing a nurturing and containing environment in order to enhance their self-esteem, to feel proud and not ashamed of taking medication; thereby indirectly preventing them from being delinquents. Like many other illnesses, ADHD needs not to be seen as a personality trait but rather as an illness that can be controlled through adherence to the medication.

To the best knowledge of the authors, other than the two studies mentioned above, no empirical studies could be located nationally and internationally that investigated the perceptions of adolescents with ADHD. Therefore, the current study attempted to close the gap from an African contextual perspective.

\section{Methods}

\subsection{Context of the study}

This study was conducted in Chris Hani Baragwanath Hospital, Child, Adolescent and Family Unit in South Africa. The hospital situated south west of the city of Johannesburg, on the southern border of the township of Soweto. Soweto was classified as 'blacks only' which comprised the Indians, Coloureds and Africans under apartheid legislation (the Group Areas Act). The demographics have changed dramatically as a result of rapid urbanization 
and overcrowding due to large immigrant population of people from all corners of the country and other countries in Africa (Vogel \& Holford, 1999). It is largely responsible for the health needs of approximately 5.5 million Soweto residents. Laning, Roake, Glynis and Horning (2003, p.8) describe Soweto as "one of the largest black cities on the African continent, with an eclectic mix of ethnic groups from South Africa and beyond...many holding proudly to their traditional cultural heritage while enthusiastically embracing the modern western way of life". The Child, Adolescent and Family Unit was selected as the research because of children with attentional and behavioral difficulties are referred to the Unit.

\subsection{Sampling}

Once access and permission to use the Unit as a site was granted, the researchers together with the head psychiatrist set out criteria for selection of participants. This included identification of potential participants by psychiatrists during their follow-up consultations; outpatients between the ages of 13 and 16 years, ability to speak English fluently; adolescents who have been diagnosed with ADHD for over six months. Although 14 potential participants were invited only five accepted the invitation. There was one female and four males with age range of 13-14 years. Racially, there were three blacks, one white and one Indian.

\subsection{Procedure}

The sample was obtained in two ways. The first method required the psychiatrists to identify potential participants during their follow-up consultations by using a screening form, which comprised brief demographic areas, namely, name, age, date of birth, grade, gender, mainstream or non-mainstream school. In addition, the following criteria were applied: participants were to be outpatients diagnosed with ADHD, between 13 and 16 years of age and be able to speak English fluently. The psychiatrists identified potential participants and attained informed consent from the parent for the researchers to make telephonic contact with them. In this way, the researchers obtained permission from the parents themselves and were able to explain the research study in detail. The second method used to obtain the sample required the head psychiatrist along with the psychiatric nursing staff to scan the log book patient diagnosed with ADHD. Adolescents who had attended within the previous three to four months were short-listed. Since it is customary for the nurses to make follow up telephone calls to patients, it was decided that in the spirit of these follow up calls, the nurses would use this as an opportunity to contact the parent of the adolescents that were short-listed. The nurses were instructed to stress to the parents that involvement in the study was not part of their treatment and that the study was completely voluntary. There were difficulties with incorrect and nonexistent telephone numbers. However despite this, the second method proved a far more successful way of obtaining the sample.

Once the researchers received verbal consent to contact the parents the study was explained to them in detail. The details included confidentiality, the voluntary nature of the study was time, place, length of the interview, and transport costs. The researchers also spoke with the participants to establish an initial connection. 


\subsection{Data collection}

Data was collected via semi-structured interviews which lasted approximately an hour. The interviews were audio recorded. The focus of the interviews was on how the participants perceive the disorder, their competence and their relationships. Amongst the questions that were asked included, "why do you think you come here to this Unit in Baragwanath hospital? How is your behavior in the classroom? How do you understand your behavior? How easy or difficult is it for you to concentrate and learn in classroom? What is it like for you when you have to listen in class and take down the instructions? How do you get on with your peers and educators? At school have you been teased or involved in a fight because of the way you behave? If so, explain how. Are you taking medication for your concentration? If so, how do you find the medication? What do you think a concentration problem is? Is it difficult for you to sit still in your seat? Please explain. What does it feel like to have this problem? Please explain what you think of yourself? Do you ever find that your mind wanders at home like it does at school? Explain how. What are the things that have helped you with your concentration? What do you think you need to help yourself? How is your scholastic performance?

\section{Data analysis}

The audio-taped interviews were transcribed verbatim. This is a consistent method of representing verbal data in written form and it included emphasis of words, significant pauses, interruptions and overlaps in speech. The textual data underwent classical thematic content analysis (Krippendorf, 1980) to facilitate the authors' understanding of the interviews, through the interpretation of emerging themes. Thematic content analysis allows for systematic examination of the data to record the relative incidences of themes (Welman \& Kruger, 2001). Common and recurrent themes in the text were identified by creating a list of categories that reflected the major themes. The identified themes were then coded and categorized (Neuman, 2006), and this was followed by analysis and interpretation of the participants' experiences (McMillan \& Schumacher, 2001).

\subsection{Ensuring trustworthiness of the data}

In order to ensure the trustworthiness of the analyzed data, certain checks were put in place to verify the data and the analysis (Fade, 2003). The first author, a highly trained and experienced academic in conducting qualitative research oversaw implementation of the study. Trustworthiness was further enhanced by peer examination (the supervisor reviewed the work at all stages).

\subsection{Reflexivity}

Before the results are presented, the authors discuss their reflections, observations and experiences during the data collection. What proved to be productive in the interview were the ways in which the second author's tone and intonations were used. This facilitated the probing method, as questions needed to be non-invasive and non judgmental in order to create a safe and trustworthy climate. Eye contact, reflecting on participants' responses, as 
well as nodding were other crucial mechanisms used to show the participants that they were being heard and understood.

The non-verbal behavior in interview should not be ignored as they can subtly reveal more than the words are able to do. For example, the participants displayed behavior that depicted typical characteristics of ADHD. One participant frequently fiddled and played with the strings of his tracksuit top. Another, on three occasions during the interview was distracted by the tape recorder and took moments to see himself whether or not the tape was functioning. Another two often played with their fingers and rubbed their hands together. It is important to remember that these young people, who had been diagnosed with ADHD, were enduring approximately a 60 minute interview that seemed to be a challenge to them.

Emotions were also displayed non-verbally. At times, the voices of participants became very soft when they were discussing peer difficulties and poor scholastic performance. Their softspoken responses displayed their vulnerability. One female participant expressed her feelings through tears. Her responses in text do not appear to be emotional, however during the interview tears streamed down her face.

\section{Results and discussion}

This section presents the results of the study concurrently with the discussion. Based on thematic content analysis, four themes emerged from the data analysis, namely, problems; belief in medication; emotional distress and retribution; and feelings of worth.

\subsection{Problems}

All the participants reported having behavioral and cognitive problems which had adverse effects on their learning. These problems were largely experienced within the context of the classroom, as demonstrated by the following excerpts.

"I used to talk in class; I wouldn't get my work done... it was difficult to sit still, sometimes I used to stand up, watch the window and think"

"You need to finish your schoolwork... you play around, you don't do your schoolwork that you are supposed to do..."

"... I fiddle; I don't sit still... I move around... I walk around"

"Sometimes when the teacher talks, you don't concentrate and you look at somebody else...you stare at that person for long"

These excerpts appear to be consistent with Barkley's (2000) description of ADHD as a problem of behavioral disinhibition and consistent lack of persistence to sustain attention. It appears from these results that the ADHD impacted adversely on the participants' learning as they struggled to sit still, in order to be receptive to learning, as well as to complete the given tasks. Not only were these adolescents disruptive to their own learning, but to other learners as well, due to their inability remain seated. The current findings also mirror the results conducted in western countries in which the theme 'problems' emerged as the dominant theme and it comprised learning, cognitive and behavioral problems (Kendall et al., 2003). 


\subsection{Belief in medication}

A powerful and dominant theme that emerged from this study was also the belief in medication. All the adolescents in the present study believed that taking medication was beneficial to them, and appeared to view medication and their experiences of ADHD as inextricably intertwined. Despite other treatment modalities available, they reported only about pills. They made a strong association between taking medication and their behavior and performance at school. The general trend was that medication improves their concentration in the classroom, inhibits their urge to talk excessively or give up from their seats and control their aggressive tendencies.

"When I take the tablets I don't talk a lot in class. They help me out a lot... it helps me in class to do my work and finish my work"

"I feel I can concentrate better...'cos my grade seven marks were high"

"I'm okay now. Sometimes I used to like get ten out of twenty and now I get twenty out of twenty for spelling. For maths I used to (sic) get nine out of hundred"

"Like if I am on the tablet then I would sit still and time would go so fast and when I look again the day is finished... well, before I was on the tablet I didn't have Ritalin and then I would never get my work finished"

"My term papers were very bad and since I have been on it (Ritalin), my papers have been good. In my old school all my exams used to be below 30\% and this one that I just got back recently, I got like a very good mark. Information used to go in one ear and come out the other, when now it just sits there"

“...because like in Grade 4, when I did not take my medication, my teacher used to see fast that I didn't take it. It helped me really it did help me 'cos now I can sit nicely like this..."

"I feel happier now"

There was a belief from the participants that the pills assisted them in their learning and as a result their scholastic performance improved. These results are consistent with previous empirical study in which the pills were seen to have positive outcomes (Kendall et al., 2003).

Medication was perceived to be helpful in controlling ADHD symptoms. Regarding interventions, their management of the disorder, all the participants perceived medication to be the primary intervention. All confirmed that the tablets they were taking were called Ritalin. They all felt their way of supporting themselves and managing their disorder was by remembering to take their medication. This was their way of taking responsibility. They all knew at what time of day they should take their medication. Furthermore, their responses indicated that they had been assisted by their teachers over the years. As they literature states, this is the one type of medication where teachers are happy to remind and assist their students in taking their medication (Rains \& Scahill, 2004). When the participants were asked what they thought helped them the most, one responded, "the tablets of course". Another response to this question was, "here, the people at the hospital that give me the tablets". 
Although the responses were largely pro-medication, there were some ambivalent feelings towards taking medication. For instance, one participant made it clear that while the medication helped her, she had the experience of being teased about taking tablets and she subsequently perceived herself to be imperfect because of this. When she made these comments in the interview she was emotional and tearful.

"I just tell them (learners) you don't understand. They don't understand. That's why I got (sic) problems with concentration. But now - my teacher say (sic) maybe I will stop to take medication because I'm okay now. Because now, you know the last time my pills were finished, I didn't do anything like stand up. I just sit. So I talk to myself, I can do this without taking my pills'. Like the nurse in the school, she gives us (sic) our pills. Like I asked her, 'can I stop to take pill?' she told me I must talk to my teacher first. There is (sic) some of my friends who stopped medication 'cos they are fine".

\subsection{Emotional distress and retribution}

It was interesting to note how subtly feelings of exclusion, embarrassment, disappointment and hurt were presented in the interviews. In each case, the tone of the interview changed when delicate material was conveyed. One participant did not so much speak about her feelings but displayed them non-verbally. She was able to speak with confidence and put her thoughts across but she was tearful throughout the interview.

"Ja, like at school, it is not nice to see that my reports are bad. Like we doing (sic) a test and the teacher reads out marks and it's bad"

"It feels bad, like...it sucks ...not nice".

"I' $m$ in the remedial class. Let's just say when I failed a test, I felt sad"

These findings corroborate Dumas and Pelletier's (1999) study, whereby it was found that preadolescents with ADHD had lower perceptions of self-worth than their counterparts in terms of scholastic competence, social acceptance and behavioral conduct. Scanlon (2006) concurs that learners with ADHD develop negative self-perceptions because of negative connotations made about their abilities when compared to other learners who do not have ADHD. Given their already compromised self-esteem, it seems critical that educators avoid actions that may be embarrassing to the learners, since actions like that may not only alienate them but also lead them to develop negativity towards school and eventual drop out of school. Elbaum and Vaughn (2003) make a significant point that learners with ADHD and other learning difficulties usually have a low academic self-concept as a result of experiences of emotional, scholastic and social failure early in their school career. It is therefore pertinent that educators and parents are not only understanding, but that they are also nurturing and accommodative of these learners.

As a result of being teased for taking the medication and not performing well at school, there was a general feeling of the need to defend oneself. Although some participants had thoughts of retaliating, the others were actually physically aggressive.

"I had to stay back from grade 6 and now, today the grade 7 has been teasing me. Everyone says I failed and it makes me feel like hitting them" 
They were swearing at me (sic) and then I got angry. It wasn't physical. We almost became physical. I was just sitting in class doing my work then I was just thinking, thinking, thinking, then they start swearing me..."

"They would tease me, say bad things or when they disrespect a woman...ja... and like Grade 7 has teased me and he's also fighting with my friends. I don't like that I have felt like hitting him. I just wanna hit them because I don't like being made fun of"

"Sometimes I get cross if someone even teases me. I get cross and I can't control my anger. Some people don't want to be my friend".

"Like sometimes, me (sic) and my friend used to get into trouble because we hit some other people. He was teasing because...we are taking pills, we mad ... whatever ...he was saying things like that. But now, no more, no more teasing. I haven't had someone teasing me in class. Sometimes they ask me why I take medication. I just tell them because of my concentration and they say 'okay', because they thought I was taking it just for fun"

These results appear to be in line with Hutchins' (2005) view that learners with ADHD commonly experience humiliation, embarrassment and high levels of stress as educators and parents often expose their weaknesses. It appears from these excerpts that these learners may be experiencing double victimization. In addition to experiencing symptoms of ADHD which impairs their learning, they are also teased and ridiculed. As a result of such feelings, they retaliate by hitting other learners. Since they are wearing the label of being 'disruptive' they may be perceived by their significant others (educators and parents) as instigators of trouble. It is not surprising then that adolescents with ADHD were found to have fewer friends, lower self-esteem and poorer psychosocial adjustment than those without ADHD (Houghton, 2006).

In this study two participants spoke about being mean to the other learners. Their disinhibited behavior and anger seem to have acted as a defense to protect their vulnerability. The following accounts demonstrate how feelings of inadequacy, hurt and pain can at times lead to bullying.

"I used to be very mean. I used to always hurt kids smaller than me"

"I feel like hitting the guy's face in, but I've gotta (sic) control myself because I don't want to get myself kicked out of school"

Brown (2005) notes that if ADHD is not well managed through skills training and medication, conduct disorder and oppositional defiant disorder can develop during the adolescent years. It is therefore crucial that adequate and appropriate treatment is provided.

\subsection{Feelings of worth}

Despite the terrible feelings and difficulties they experienced as a result of having ADHD, these learners spoke positively of themselves. Whether or not these extracts are inflated perceptions of the self, they reflect the need to feel worthy and competent.

"I'm good, I'm intelligent and jolly"

"I would say I'm cheerful, happy, and just okay" 
"I don't struggle in class, it's just okay, and it's not hard"

"I am okay now, no more teasing and I am able to achieve academically"

Since the symptoms of ADHD must be present before the age 7 years for a diagnosis to be made, it can be deduced that for most of their school years they receive attention for bad behavior. If this is the case, who will reframe their identity positively? They will. Krueger and Kendall (2001) are of the opinion that children with ADHD are likely to have exaggerated self-perceptions and these perceptions tend to serve as a self-protective mechanism to ward-off feelings of inadequacy and helplessness. Although one cannot conclude from these excerpts whether the participants were overestimating their competence and exaggerating their sense of well-being, it is encouraging to realize that they too would prefer to be valued and appreciated. This reminds us then that by being disruptive or even aggressive towards other learners, it may be a cry for help. It is therefore upon the adults to psycho-educate them about alternative adaptive ways of managing their behavior, without getting into trouble.

\section{Limitations of the study}

The research was qualitative in nature and the size and character of the sample do not allow for generalization of the research findings to the population as a whole. The sample selected in this study was sourced from a specific medical context. A variety of participants selected from support groups, schools or those who are patient in private practice may have added an interesting dimension to the experiences and self-perceptions of adolescents with ADHD.

The study did not manage to delve into the family life of adolescents with ADHD. The school setting appeared to pre-dominate the interviews. To gain a fuller understanding of the associated problem of ADHD, insight into life at home would have been a valuable component to the study. Given that this study is the first to be conducted within the African continent, it should therefore be seen as an exploratory study.

\section{Implications of the study}

The implications of this study emphasize the existence of ADHD in the everyday life of those who have it. The feeling and perceptions of the participants bring the 'human element' to this disorder. Their vulnerability, the emotional distress, the need to be acknowledged and recognized highlight the reality of this disorder. The description of their behavior, the account of their pain, and the struggles with scholastic performance all point to the fact that ADHD is not outgrown during adolescence. It is hoped that the more ADHD is really understood, the more effort can be made on the part of the parents, educators and professionals to alleviate some of the difficulties of the problem. Knowledge of the experiences of learners with ADHD will not only enable educators to appreciate and accommodate these learners in their classrooms by adapting their teaching programmes and methods, but will also enable them to use the strengths of these learners as point of departure in educating them (Holz \& Lessing, 2002).

As reported in literature review, for a child or adolescent to be diagnosed with ADHD according to the DSM-IVR, some impairment of concentration must be present both at home 
and at school. The authors found that the participants did not perceive concentration to be a problem at home. Their responses indicated that they felt less challenged by their difficulties in their home environment.

It is interesting to note that at no point in the interviews did the participant use the label 'ADHD' or Attention Deficit Disorder (ADD) to describe their difficulties. Their descriptions however, show that they understand where their difficulties lie. Furthermore, at no point during the interview did they use the word 'attention', 'hyperactive' 'impulsive' or 'distractible'. These terms do not appear to be a part of their vocabulary or thinking even though they are used not only in the medical, educational and psychological field, but also in popular culture.

Poor scholastic performance is commonly linked with ADHD (Venter, 2009) - that of low self-esteem affects scholastic achievement and emotional adjustment. In turn, poor scholastic performance affects self-esteem (Desai, 2003). What is evident from these results is that the participants felt acutely sensitive about their ability to achieve. Their comments about failure, performing at school and their tone in the interviews all indicated feelings of disappointment, exclusion and inadequacy.

The desire to be validated, worthy and competent is not exclusive to the individual with ADHD. It is something which all human beings search for. But for the adolescent with ADHD, the need is heightened. Their school years are known to be the worst time of their lives as they are placed in an environment which is discouraging, especially by their peers (Pooley, 2002).

The participants placed importance on the need to feel worthy and competent. They initially acknowledged their pain and difficulties. They were also able to find ways to feel a sense of competence and worthiness. They tended to build a 'happy' picture for themselves regardless of their negative experiences. Furthermore, the participants' comments about needing to feel competent emphasize the significance of acknowledging children and adolescents with ADHD for any amount of effort they may display. To fuel their feelings of worth and competence, it is necessary for their support network system to praise and recognize their strengths and talents. Recognizing their value and detecting any form of competence is a means of supporting them (Hallowell \& Ratey, 1994). This is confirmed by another study, which revealed that children with ADHD had fewer adjustment problems when they perceived that they had social support (Demeray \& Elliot, 2001).

\section{Conclusion}

This study aimed to explore and examine the experiences, feelings and self-perceptions of adolescents who have ADHD. The sample was selected from Chris Hani Baragwanath's Child and Adolescent Psychiatric Unit. The findings and the interpretation indicate that the adolescents have insight into their difficulties. Descriptions of their behaviors and difficulties match the commonly known symptoms of ADHD. It was found that the adolescents use the term concentration problem as an umbrella term to define their difficulties. Regarding the perception around treatment and intervention, the adolescents support the use of medication. The adolescents however, had little to say about other forms of intervention. Another important finding is the participants' experiences of being teased. This appears to have a detrimental effect on their self-esteem. Their self-esteem is also 
severely impacted by their difficulties to perform adequately at school and scholastic performance proves to be one of major problem the adolescents' experience. Due to these difficulties, it was found that learners with ADHD have a greater need to feel competent and valued.

The findings of the study reveal that the participants do not outgrow ADHD once they reach adolescence nor are their associated problems resolved. The themes explicitly show that ADHD is not benign and affects the day-to-day experiences of the adolescent. For the participants, the school environment is the place where their difficulties and challenges come to the fore. From scholastic performance to peer relationships, ADHD has had an impact on their well-being. Several participants spoke about their vulnerabilities and pain and they also indicated their need to feel competent and worthy. Finally, the participants displayed no qualms about taking medication and to some extent, believe that it has been a cure for their difficulties.

\section{Acknowledgements}

The authors would like to thank Sue Thompson who provided expert guidance in the conceptualization and implementation of the study.

\section{References}

Aase, H, Meyer, A \& Sagvolden, T. (2006). Moment to Moment dynamics of ADHD behavior in South African children. Behavioral and Brain Function, 2:11 doi:10.1186/1744-9081-2-11

Adewuya, A. O. \& Famuyiwa, O.O (2007). Attention deficit hyperactivity disorder among Nigerian primary school children Prevalence and co-morbid condition. European Child Adolescent Psychiatry, 16, 10-15.

Amen, D.G. (2001). Healing ADHD. New York: Berkley Books.

American Psychiatric Association (1994). Diagnostic and statistical manual of mental disorders: $D S M-I V .4^{\text {th }}$ ed.) Washington D.C.

Barkley, R. (1990). Attention Deficit Hyperactivity Disorder: A Handbook for Diagnosis and treatment. New York: The Guilford Press.

Barkley, R A (1998) Attention Deficit Hyperactivity Disorder: A Handbook for Diagnosis and treatment. (2nd Ed.) New York: The Guilford Press.

Barkley, R.A. (2000). Taking charge of ADHD. Revised edition. New York: Gilford Press.

Biederman, J., Willens, T.E. \& Spencer, T. J. (2002) Attention Deficit/Hyperactivity Disorder across the Lifespan. Annual Review of Medicine, 53, 113-132.

Bird, H.R. (2002). The diagnostic classification, epidemiology and cress cultural validity of ADHD, in Attention Deficit/Hyperactivity Disorder: State of the Science: best practices. Kingston, NJ, Civic Research institute.

Bradley-Klug, K. \& Grier, J. (2000). Adolescents and their Families: Coping with ADHD. School Psychology Quarter, 15(4), 480-486.

Brown, T.E. (2005). Attention Deficit Disorder: the unfocused mind in children and adults. New Haven: Yale University Press.

Bryant, P. \& Coleman, A. (1994). (Eds.) Developmental Psychology. (pp.54-62). New York: Longman. 
Conners C. K. \& Jett, J.L. (2001). Attention Deficit Hyperactivity Disorder. Kansas City: Compact Clinicals.

Demeray, M.K. \& Elliot, S.N. (2001). Perceived social support by children with characteristics of attention deficit hyperactivity disorder. School Psychology Quarterly, 16 (1), 68-91.

Desai, A. (2003). The impact of learning in a second language and academic competence on learners' self-esteem: a study of grade four girls from 2 schools in Gauteng. Unpublished master's thesis, University of the Witwatersrand, South Africa.

Dumas, D. \& Pelletier, L. (1999). Perception in hyperactive children, Maternal Child Nursing, '24, 12-19.

DuPaul, G.J., Power, T. J., Anastopoulos, A. D., Reid, R., McGoey, K., \& Ikeda, M. (1997a). Teacher ratings of ADHD symptoms: Factor structure and normative data. Psychological Assessment, 9, 436-444.

DuPaul, G.J. \& Stoner, G.R.A. (1994). ADHD in the schools: Assessment and intervention strategies. New York: Guilford.

Elbaum, B. \& Vaughn, S. (2003). Self-concept and students with learning disabilities. In H.L. et al. (Eds.). Handbook of learning disabilities. New York: The Guildford Press.

Fade, S.A. (2003). Communicating and judging the quality of qualitative research: the need for a new language. Journal of Human Nutrition Dietetics, 16, 139-149.

Goldman, L.S., Genel, M., Bezman, R.J. \& Slanetz, P.J. (1998). Diagnosis and treatment of Attention Deficit/Hyperactivity Disorder in children and adolescents. Journal of the American Medical Association, 278(14), 1100-1107.

Goldstein, S. \& Goldstein, M. (1998). Managing ADHD: A Guide for Practitioners. New York: John Wiley \& Sons Inc.

Gross, M. A. (1997). The ADD brain diagnosis treatment and science of Attention Deficit Disorder $(A D D / A D H D)$ in adults, teenagers and children. New York: Nova Science

Hallowell, E.M, \& Ratey, J.J (1994) Answers to Distraction. New York: Bantam Books.

Holz, T. \& Lessing, A. (2002). Reflections on Attention Deficit Hyperactivity Disorder (ADHD) in an inclusive system. Perspectives in Education, 20(3), 103-110.

Houghton, S. (2006). Advances in ADHD research through the lifespan: common themes and implications. International Journal of Disability, Development and Education, 53(2), 263-272.

Hutchins, P. (2005). Helping children with learning disabilities and ADHD: working together, from inclusion to belonging congress. Nedbank Sandton Auditorium and Conference Centre, Sandton, 12 May.

Kendall, J. (2000). Outlasting disruption: The process of reinvestment in families ADHD children. Qualitative Health Research, 8(6), 839-857.

Kendall, J., Hatton, D., Beckett, A., \& Leo, M (2003).Children's Accounts of Attention Deficit Hyperactivity Disorder. Advances in Nursing Sciences, 26(2), 114- 130.

Krueger, M. \& Kendall, J. (2001). Descriptions of self: An exploratory study of adolescents with ADHD, Journal of Child and Adolescent Psychiatric Nursing, 14(2), 61-73.

Krippendorff, K. (1980). Content Analysis: An introduction to its methodology. Newbury Park, CA: Sage.

Laning, H., Roake, N., Glynis, \& Horning, G. (2003). Life Soweto Style. Cape Town: Struik Publishers. 
Lambert, N. \& Hartsough, C. (1998). Prospective study of tobacco smoking and substance dependencies among samples of ADHD and non-ADHD participants, Journal of Learning Disabilities, 31, 533-544.

Louw, C., Oswald, M.M. \& Perold, M.D. (2009). General practitioners familiarity, attitudes and practices with regards to Attention Deficit Hyperactivity Disorder (ADHD) in Children and Adults, South African Family Practice, 51, 152-157.

Mahomedy, Z., van der Westhuizen, D., van der Linde, M.J. \& Coetsee, J. (2007). Persistence of Attention Deficit/Hyperactivity Disorder into adulthood: A study conducted on parents of children diagnosed with Attention Deficit/Hyperactivity Disorder, South African Psychiatry review, 10, 93-98.

Mash, E.J. \& Wolfe D.A. (2005). Abnormal Child Psychology. 2nd edition. Belmont: Wadsworth.

McMillan, J. H., \& Schumacher, S. (2001). Research in education: A conceptual introduction (5th Ed.). New York, NY: Longman.

Mercugliano, M. (1999). What is ADHD? Pediatric Clinics of North America, 46, 831-843.

Meyer, A., Eilertsen, D.E., Sundet, J.M., Tshifularo, J. \& Sagvolden, T. (2004). Cross culture similarities in ADHD - like behavior amongst South African primary school children, South African Journal of Psychology, 34(1) 122-138.

Nahlik, J. (2004). Issues in Diagnosis of Attention Deficit /Hyperactivity Disorder in Adolescents. Clinical Pediatrics, 43(1), 122-138.

Nauert, R. (2009). Perception of ADHD behavior may be placebo-induced. June 16 2011, from http:/ / psychcentral.com/news/2009/06/40/perception-of-adhd-behavior-maybe-placebo-induced/6809.html.

Neuman, W.L. (2006). Social research methods: qualitative and quantitative approaches, $6^{\text {th }}$ edition. Boston: Pearson Education.

Perold, M, Louw, C. \& Kleynhans, S. (2010). Primary school teachers' knowledge and misperceptions of attention deficit hyperactivity disorder (ADHD). South African Journal of Education, 30, 457-473.

Polanczk, G., de Lima, M.S, Horta, B.L, Biederman, J. \& Rohde, L.A. (2007). The worldwide prevalence of ADHD: A Systemic review and metaregression analysis, American Journal of Psychiatry, 164(6), 942-948.

Pooley, S. (2002). Names don't count. A guide to ADHD for parents. ADHD Support Group for South Africa.

Rains, A. \& Scahill, L. (2004). New long-acting stimulants in children with ADHD. Journal of Child and Adolescent Psychiatric Nursing, 17(4), 177-180.

Rhee, S.H., Waldman, I.D., Hay, D.A. \& Levy, F. (1999). Sex differences in genetic and environmental influences on DSM -III-R Attention - Deficit Hyperactivity Disorder, Journal of Abnormal Psychology, 108(1), 24-41.

Robin, A.L. (2002). Lifestyle issues. In Goldstein, S. \& Ellison, A.T. (Eds.), Clinician's guide to adult ADHD: Assessment and intervention. San Diego: Academic Press.

Scanlon, D. (2006). Learning disabilities and attention deficits. In Thies, K.M. \& Travers, J.F. (Eds.). Handbook of Human Development for Health Care Professional. Sudbury: Jones and Bartlett Publishers.

Schroeder, C.S. \& Gordon, B.N, (2002). Assessment and Treatment of Childhood Problems (2nd ed.). London: The Guilford Press. 
Seabi, J. (2010). Foundation phase educators' perceptions of Attention Deficit Hyperactivity Disorder at a mainstream primary school. Journal of South African Higher Education, 24(4), 616-629.

Timimi, S. \& Taylor, E. (2004). ADHD is best understood as a cultural construct, British Journal of Psychiatry, 184, 8-9.

Van der Westhuizen, A (2010). Attention deficit Hyperactivity disorder (ADHD), South African Pharmaceutical Journal, 10-20.

Vogel, W. \& Holford, L. (1999). Child psychiatry in Johannesburg, South Africa. A descriptive account at two clinics in 1997, European Child $\mathcal{E}$ Adolescent Psychiatry, 8 , 181-188.

Welman, J.C. \& Kruger, S.J. (2001). Research Methodology (2nd ed.) Oxford University Press: Cape Town. 


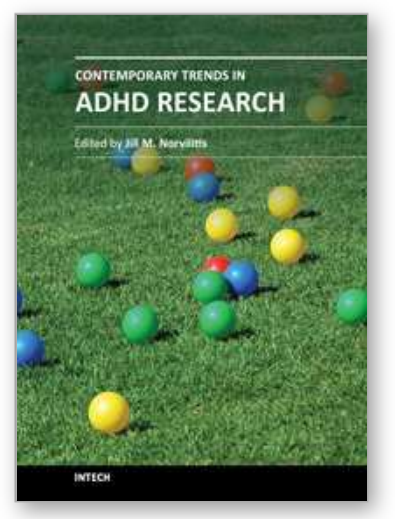

\section{Contemporary Trends in ADHD Research}

Edited by Dr. Jill M. Norvilitis

ISBN 978-953-307-858-8

Hard cover, 196 pages

Publisher InTech

Published online 15, February, 2012

Published in print edition February, 2012

With many children and adults affected by Attention Deficit Hyperactivity Disorder, researchers strive to understand the underpinnings of ADHD and associated factors on both a basic and applied level. The goal of this volume is to explore some of the broad array of research in the field of ADHD. The 12 chapters cover a variety of topics as varied as postural control, endocrine dysfunction, juvenile justice, and academic outcomes. These chapters will provide valuable insights for students reading about ADHD for the first time, researchers wishing to learn about the latest advances, and practitioners seeking new insight in the field.

\section{How to reference}

In order to correctly reference this scholarly work, feel free to copy and paste the following:

J. Seabi and N.A. Economou (2012). Understanding the Distracted and the Disinhibited: Experiences of Adolescents Diagnosed with ADHD Within the South African Context, Contemporary Trends in ADHD Research, Dr. Jill M. Norvilitis (Ed.), ISBN: 978-953-307-858-8, InTech, Available from:

http://www.intechopen.com/books/contemporary-trends-in-adhd-research/understanding-the-distracted-andthe-disinhibited-experiences-of-adolescents-diagnosed-with-adhd-wit

\section{INTECH}

open science | open minds

\section{InTech Europe}

University Campus STeP Ri Slavka Krautzeka 83/A 51000 Rijeka, Croatia Phone: +385 (51) 770447 Fax: +385 (51) 686166 www.intechopen.com

\section{InTech China}

Unit 405, Office Block, Hotel Equatorial Shanghai No.65, Yan An Road (West), Shanghai, 200040, China 中国上海市延安西路65号上海国际贵都大饭店办公楼 405 单元 Phone: +86-21-62489820

Fax: +86-21-62489821 
(C) 2012 The Author(s). Licensee IntechOpen. This is an open access article distributed under the terms of the Creative Commons Attribution 3.0 License, which permits unrestricted use, distribution, and reproduction in any medium, provided the original work is properly cited. 